\title{
Evidence to Support a Putative Role for Insulin Resistance in Chronic Kidney Disease
}

\author{
Walid Shehab-Eldin ${ }^{\mathrm{a}}$, Ahmed Ragheb ${ }^{\mathrm{a}}$, Sana Gazarin ${ }^{\mathrm{b}}$, Ahmed Shoker $^{\mathrm{a}^{*}}$ \\ a. Royal University Hospital, Department of Medicine, University of Saskatchewan, Canada. \\ b. Internal Medicine Department, Faculty of Medicine, Menoufya University, Egypt.
}

\begin{abstract}
Introduction: The primary cause of morbidity and mortality in the renal patient is a cardiovascular event. Insulin resistance (IR) contributes to this event by increasing cardiovascular disease (CVD) and accelerating rates of decline in kidney function. Here we review the historical background of IR in patients with chronic kidney disease (CKD) and present evidence for a role of IR in accelerating cardiovascular and renal diseases.
\end{abstract}

Review: The high prevalence of IR in CKD patients is well documented. It is suggested that increased IR in the renal patient is caused by uremia as well as by other known factors in the general population. Patients with CKD have an alarmingly high risk for cardiovascular morbidity and mortality. There is overwhelming evidence to support a role for IR in increased CVD morbidity and mortality in the general population, which is likely to extend to CKD patients. Some of the traditional treatment measures for IR, such as metformin, may not be applicable to the renal patient. Other options include weight reduction, exercise, treatment of anemia to improve exercise tolerance, treatment of vitamin D deficiency, thiazolidinediones, and dialysis. IR is estimated by studying the relationship between blood glucose and the concomitant insulin level. Such measurement may help identify patients at increased risk for future cardiovascular events and guide treatment measures.

Conclusion: Sufficient evidence supports the increased prevalence of IR in kidney patients. Treating IR may retard the progression of CKD and decrease the incidence of cardiovascular events in this high risk population.

* Corresponding author; Director of Transplant Program, Department of Medicine, University of Saskatchewan, 103 Hospital Drive, Saskatoon, SK S7N 0W8, Canada; E mail: ass787@mail.usask.ca
Keywords: chronic kidney diseass, cardiovascular disease, insulin resistance

\section{Introduction}

Insulin resistance (IR) is defined as a state of diminished responsiveness of many tissues to insulin. To overcome the diminished responsiveness to insulin action, the pancreas responds by producing more insulin, reaching a new steady state at which a higher than normal insulin level is needed to maintain internal homeostasis. Meanwhile, the kidney and blood vessels maintain a normal response to insulin, so as a result these important organs are negatively affected by the increased insulin level. Thus, IR manifests itself in two complementary pathological sets of derangements. First, manifestations occur due to IR in certain tissues such as the muscles and adipose tissues. Second, heightened responses by other organs occur due to the increased insulin level such as the kidney and blood vessels.

IR in humans was first described in 1939 by Himsworth, who speculated that diabetes mellitus may result from insensitivity to insulin action as well as from its deficiency. In 1949 he documented IR in patients with diabetes mellitus. In 1979 Defrenzo et al developed the hyperinsulinemic euglycemic clamp as the gold standard method for diagnosis of IR. Sex years later, Mathew et al developed a variety of mathematical equations based on fasting insulin and blood sugar levels to estimate IR. Quantitative Insulin Sensitivity Check Index (QUICKI) is a more recent equation for estimation of $I R$ in epidemiological studies [1].

The presence of IR in uremia is well documented. In 1969, Westervelt reported IR in patients with uremia. In 1981 Defronzo et al presented an argument to support adipose tissue insensitivity as the primary site of failure to insulin action in renal patients with IR. In 1996, Dengal et al suggested a role of IR as a risk factor that accelerates the rate of decline in kidney function. 
Figure 1: The bi-directional relationship of IR and CKD and their combined effect on the cardiovascular system

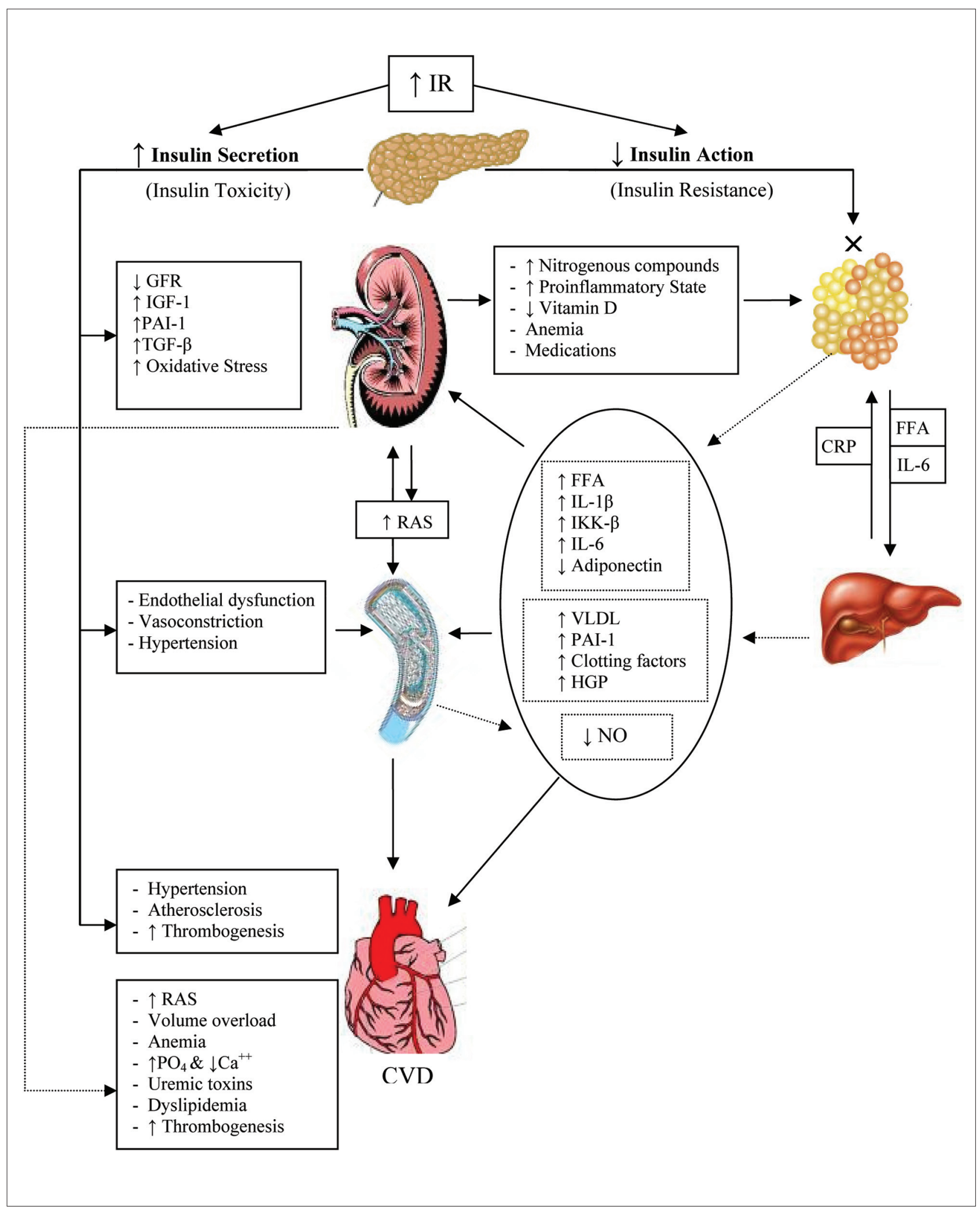

IR: insulin resistance; GFR: glomerular filtration rate; IGF-1: Insulin-like Growth Factor-1; PAI-1: Plasminogen Activator Inhibitor-1; TGF- $\beta$ : transforming growth factor-beta; RAS: renin-angiotensin system; CRP: C-reactive protein; FFA: free fatty acids; IL-6: interleukin-6; IL-1 1 : interleukin$1 \beta$; IKK- $\beta$ : inhibitor of kappaB kinase beta ; VLDL: very low density lipoprotein; HGP: hepatic glucose production; NO: nitrous oxide 
Table 1: Factors which may modify IR in the renal patient $[4,11-22]$

\begin{tabular}{lll}
\hline Renal risk factor & & Effect \\
\hline Type of kidney Disease & APKD & $\uparrow \uparrow$ \\
& IGA nephropathy & $\uparrow \uparrow$ \\
Glomerular Filtration Rate & Glomerulonephritis & $\uparrow \uparrow$ \\
Medications & & $0 / \downarrow \downarrow$ \\
& Steroids & $\uparrow \uparrow$ \\
& Diuretics & $\uparrow \uparrow$ \\
& Erythropoitien & $\downarrow \downarrow$ \\
& 1,25 dihydroxycholecalciferol & $\downarrow \downarrow$ \\
& Statin & $\downarrow \downarrow$ \\
Uremia & ACEi & $\downarrow \downarrow$ \\
Hemodialysis & Prazocin & $\downarrow \downarrow$ \\
Peritoneal dialysis & Nifedipine & $\downarrow \downarrow$ \\
Renal Transplantation & Atenolol & $\uparrow \uparrow$ \\
& & $\uparrow \uparrow$ \\
\end{tabular}

The prevalence and risks of IR in patients with cardiovascular diseases (CVD) also has been well documented. In 1977, Stout suggested that IR is an important component of the metabolic syndrome. He reported IR as a significant risk factor for cardiovascular morbidity and mortality. Shinohara, Foley, and Mann and their co-workers reported a role of IR in increased cardiovascular events in patients with chronic kidney disease CKD [2, 3]. Despite all the above-listed reports, current guidelines for the routine follow-up of patients with CKD do not include IR measurement.

Based on the above reports, however, we believe that measuring serum insulin and estimating IR should be a welcomed additional laboratory test in managing patients with CKD. This review, therefore, serves to delineate our rationale to recommend the measurement of serum insulin and estimate IR in CKD patients.

\section{Role of IR in accelerating rate of decline in renal function}

IR is well documented in patients with CKD and end stage renal disease (ESRD) [4]. Epidemiological studies suggested a significant correlation between IR and CKD. Chen et al suggested that Homeostatic Model Assessment of Insulin Resistance (HOMA-IR) increased by 1.93 is associated with a 1.5 hazard ratio of CKD prevalence [5]. Onat et al suggested that doubling HOMA-IR in men is associated with a $14 \%$ reduction in Glomerular Filtration Rate (GFR) [6]. More recently, it was suggested that HOMA-IR correlates with interstitial fibrosis diagnosed by renal biopsy $(\mathrm{R}=0.42, \mathrm{P}=0.04)$ [7]. Moreover, IR was found to precede the development of microalbuminuria, a known potent risk factor for accelerating both $\mathrm{CKD}$ and CVD.

Few studies looked at the prevalence of IR in renal patients. It was reported that $48.3 \%$ of non-diabetic, non-obese patients with CKD [8] and $31.6 \%$ of hemodialysis (HD) patients [9] have IR. Recently, the prevalence of IR was estimated at $47.8 \%$ of renal patients [7]. Three main hypotheses explain the higher prevalence of IR in kidney disease. First, IR may be causally related to CKD [5]. Secondly, IR may be a consequence of CKD. Thirdly, both IR and CKD occur as consequences of a same process, for example metabolic syndrome [10]; and there is yet the possibility of a bi-directional relationship between IR and CKD that leads to progression in kidney failure.

It is suggested that increased IR in the renal patient is caused by uremia as well as by other known factors in the general population [11] (Figure 1). Fliser et aldocumented the presence of IR even in renal patients with normal GFR. They described an association between increased IR and progression of kidney disease in two groups of patients with Adult Polycystic Kidney Disease (APKD) and IgA nephropathy. Vareesangthip and co-workers reached 
Table 2: Mean Homeostatic Model Assessment of Insulin Resistance (HOMA-IR) and/or Hazard Ratio (HR) in renal and non-renal patients with and without CVD [3, 8, 13, 16, 41-47]

\begin{tabular}{ccccccccccccc}
\hline \multicolumn{1}{c}{ Non-CKD population } & \multicolumn{1}{c}{ CKD Population } \\
\hline \multicolumn{3}{c}{ Control } & \multicolumn{3}{c}{ CVD } & \multicolumn{2}{c}{ Diabetics } & \multicolumn{2}{c}{ No CVD } & \multicolumn{2}{c}{ CVD } & \multicolumn{2}{c}{ Diabetics } \\
\hline HOMA-IR & Number & HOMA-IR & Number & HOMA-IR & Number & HOMA-IR & Number & HOMA-IR & Number & HOMA-IR & Number \\
\hline 2.5 & 721 & 2.8 & 118 & -- & -- & -- & -- & -- & -- & -- & -- \\
2.54 & 36 & -- & -- & -- & -- & 2.88 & 95 & -- & -- & -- & -- \\
1.7 & 25 & -- & -- & -- & -- & 6.87 & 239 & -- & -- & -- & -- \\
2.9 & 25 & -- & -- & -- & -- & 6 & 52 & -- & -- & -- & -- \\
-- & -- & -- & -- & -- & -- & 5.46 & 89 & -- & -- & -- & -- \\
1.39 & 76 & -- & -- & -- & -- & 3.38 & 199 & 5.12 & 28 & -- & -- \\
-- & -- & -- & -- & -- & -- & 2.4 & 35 & -- & -- & 6.3 & 27 \\
-- & -- & HR: 2.5 & 2569 & HR: 1.56 & 1326 & -- & -- & HR: 2.61 & -- & -- & -- \\
\hline
\end{tabular}

a similar conclusion in another cohort of patients with APKD. Kato et al documented increased IR in patients with glomerulonephritis diagnosed by renal biopsy even with normal serum creatinine [4].

Several types of kidney diseases are associated with IR and potential modifying effects (Table 1). Steroids, diuretics, and beta blockers are well documented risk factors for increased IR in renal patients. It should be noted that 1,25 dihydroxycholecalciferol, statins, ACE inhibitors, Prazocin, Nifedipine, and Erythropoietin were found to improve sensitivity to insulin. Both hemodialysis and peritoneal dialysis improve insulin sensitivity, while renal transplantation aggravates resistance to insulin.

Several mechanisms are suggested to explain the deterioration of renal function with increasing IR. In the general population, insulin has both vasodilator and salt-retaining effects, leading to an increase in the renal blood flow and GFR [23]. In IR, This effect is reversed and insulin leads to the reduction in GFR [24]. High-dose insulin infusion increases the renal albumin excretion in diabetic patients by about $50 \%$ without affecting systemic albumin permeability. On the other hand, a high insulin dose doesn't affect renal albumin excretion in healthy individuals, thus providing evidence of the contribution of insulin in renal injury in IR states. High insulin may also lead to renal injury by stimulating different mediators implicated in the progression of kidney disease including Insulin-like Growth Factor-1 (IGF-1), Transforming Growth Factor- $\beta$ (TGF- $\beta$ ), and plasminogen activator inhibitor-1 (PAI-1) [25].

Hyperinsulinemia increases angiotensin II-mediated aldosterone secretion and increases the pressor effect of angiotensin II by increasing activation of the sympathetic nervous system. In addition, insulin is necessary for the angiotensin II-induced contraction of mesangial cells, which is another link proving insulin- and angiotensin II-mediated renal injury. IR may also cause renal injury through the inhibition of NO synthesis, which is a known renal vasodilator molecule [26].

Insulin enhances oxidative stress both through downregulation of anti-oxidative enzymes and through stimulating free radical production [27]. Oxidative stress is implicated in the progression of CKD [28].

Low HDL cholesterol observed in IR (as discussed before) was found as an independent predictor of kidney disease progression among 840 patients with CKD in the MDRD study. Hypertriglyceridemia and low HDL were found to predict and increase the risk of CKD in 12,728 participants in the "Atherosclerosis Risk in Communities" study [29].

\section{Insulin resistance as a risk factor for CVD in renal patients}

Patients with CKD have an alarmingly high risk for cardiovascular morbidity and mortality. This applies even to patients with minor degrees of renal dysfunction [30]. In fact, most CKD patients die before reaching ESRD. Many investigators have presented a plethora of evidence to support a role for IR in increased CVD morbidity and mortality in the general population. Paradoxically, few researchers studied this correlate in CKD patients. We reason, therefore, that the evidence in the general population is so overwhelming and, by extension, urgent studies are needed to address the role of IR and its treatment in CKD patients. 


\section{Mechanisms by which IR increases risk of CVD}

\section{Insulin resistance and hypertension}

Increased insulin level enhances sympathetic activity, sodium retention, and proliferation of vascular smooth muscle cells. IR leads also to hyperglycemia, which inhibits the ADMA/DDAH pathway and thereby inhibits nitric oxide production [31].

\section{Insulin resistance and atherosclerosis}

Both the increased insulin level and the associated hyperglycemia are suggested culprits for enhancing atherosclerosis. A direct role of insulin in atherogenesis has been suggested from animal studies. Mechanistically, insulin leads to the induction of proliferation of VSMCs, switching the genes involved in connective tissue formation, upregulation of LDL-receptor activity and stimulation of the production of growth factors. On the other hand, the associated hyperglycemic inhibitory effect on NO [31] explains the endothelial dysfunction associated with IR. In addition, the resistance of the adipose tissue to insulin leads to the release of several inflammatory mediators such as IL-6 [32] and TNF $\alpha$ [33]. These mediators are known to directly affect migration of macrophages into the sub-endothelial layer leading to foam cell formation with the CD-36 receptor, which internalizes oxidized LDL [34].

\section{Insulin resistance and thrombosis}

Hyperinsulinemia induces endothelial dysfunction and enhances release of several inflammatory mediators, both of which are known to enhance the synthesis and production of several pro-coagulant factors such as von Willebrand factor (vWF), factor VIII, factor XII, factor VII, and fibrinogen. PAI-1 production is increased, likely in response to IGF-1 and TGF- $\beta$. Hyperglycemia and increased free fatty acid (FFA) production impair fibrinolysis by similar mechanisms [35].

\section{Insulin resistance and left ventricular function}

Left ventricular hypertrphy (LVH) has been associated with diabetes mellitus and abnormal glucose tolerance in several epidemiological investigations [36]. LVH is common with other endocrinal disorders associated with IR such as acromegaly and hypothyroidism [37].

Increased circulating FFAs associated with hyperglycemia in IR results in a series of metabolic adaptations and maladaptations that eventually result in intra-myocardial lipids accumulation [38]. It is hypothesized that the increased availability and uptake of lipids and fatty acids may exceed the rates of their use, resulting in lipid accumulation within the cardiomyocytes. It was also shown that hyperglycemia decreases the expression of the peroxisome proliferator-activated receptors alpha (PPAR ) and their regulating genes [39]. Thus, prolonged exposure to hyperglycemia leads to the inhibition of fatty acids metabolism, which eventually leads to the increased deposition of lipids within the cardiac cells [40]. Excessive lipids and fatty acids deposition induces Reactive Oxygen Species accumulation, iNOS, and apoptosis, which then result in contractile dysfunction through increasing the intracellular ceramide levels. Lipid deposition may also induce contractile dysfunction through other mechanisms independent from ceramide, such as chronic activation of Protein Kinase-C (PKCs). Indeed, targeted over-expression of $\mathrm{PKC} 32$ in the myocardium causes cardiomyopathy.

A number of studies determined the mean HOMA-IR in patients with and without renal disease who may or may not develop a CVD event (Table 2). Mean HOMA-IR in the general population was reported to vary from 1.39 to 2.9, based on the assay of insulin used. On the other hand, Hanley et al demonstrated a HOMA-IR hazard ratio of 2.5 in non-renal patients who develop a CVD event. A similarly increased hazard ratio of 1.6 was demonstrated in patients with diabetes who developed a CVD event while they had normal kidney function. However, the prevalence and hazard ratio of HOMA-IR were shown to be much higher in the CKD population.

After a follow-up period of approximately 5.5 years, the hazard ratio of cardiovascular mortalities in CKD patients was $2.6(95 \% \mathrm{CI}, 1.12$ to 6.01$)$ in the univariate Cox proportional hazards model of 183 non-diabetic patients with ESRD treated with maintenance hemodialysis. In the multivariate Cox models, the HR was 4.60 (95\% CI, 1.83 to 11.55 ) and was independent of age, $\mathrm{C}$-reactive protein, and the presence of pre-existing vascular complications [3].

\section{Treatment of insulin resistance in renal patients}

Although IR is prevalent and has deleterious effects in renal patients, no guidelines are available to deal with those patients. Measures in the general population couldn't be applied to renal patients, however. For example metformin, an efficient drug improving IR in the general population is contraindicated in CKD patients. Therefore, we tried in this review to locate suitable treatment options as follow:

\section{Dietary restriction}

Higher BMI is an independent predictor of CKD; in part through increased IR [48]. Dietary restriction improves HOMA-IR in the general population [49]. In 
Table 3: Reasons to justify measurement of insulin resistance in the renal patient

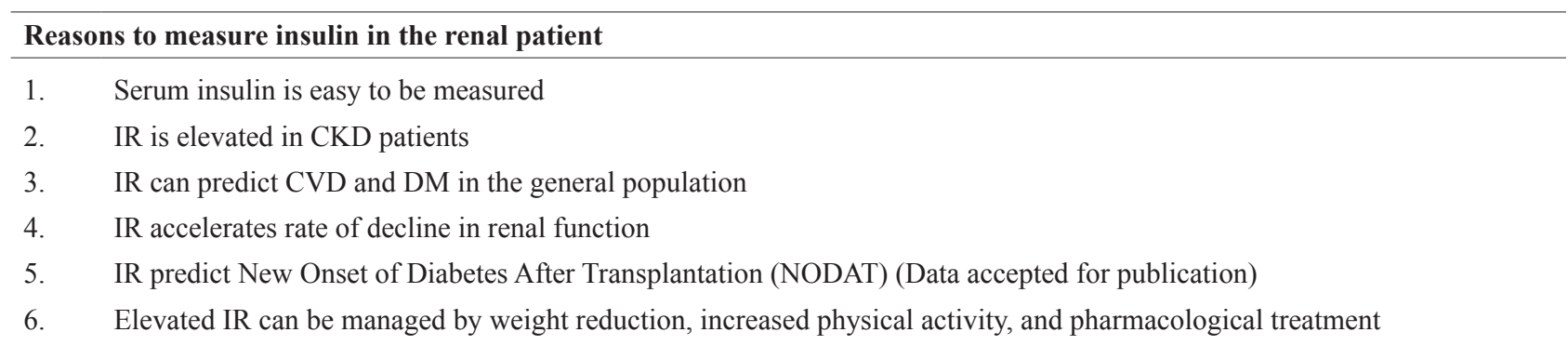

CKD patients, protein restriction reduces the production of nitrogenous compounds which may increase IR. On the other hand, dietary restriction may have deleterious effects and obesity provide a survival advantage for patients with ESRD [50, 51].

\section{Exercise}

There is no doubt that exercise improves IR. The same is applied to ESRD patients on HD. Renal patients, however have limited physical function [52]. Actually, they have only half the exercise capacity of the normal sedentary individuals [53]. In addition, the increased CVD risk in this population could be aggravated by exercise.

In spite of these limitations a multidisciplinary program combining diet and exercise suggests that significant weight loss and improved physical functioning can be achieved in CKD patients [54].

\section{Treatment of contributing factors}

\section{a. Treatment of anemia}

Correction of anemia by erythropoietin [55] or intravenous iron [56] in HD patients showed an improvement of insulin sensitivity. This improvement may be due to improved exercise tolerance.

\section{b. Treatment of vitamin D deficiency}

Insulin sensitivity was normalized after 3 months of intravenous calcitriol treatment in uremic patients. Serum 1,25-(OH)2 D 3 levels in vitamin-D-deficient renal patients could be raised indirectly by correction of metabolic acidosis.

\section{Thiazolidinediones}

Glitazones is a relatively new anti-diabetic group of drugs known to improve IR [57]. CKD patients treated with pioglitazone are less likely to develop end point of all-cause death, and specifically CVD mortality independent of the severity of renal impairment [58]. Although these drugs could be used in renal patients without dose adjustment, some rare adverse events, (weight gain, oedema, fluid retention, etc.), may limit their use in some patients [59]. However, concerns about the safety of this group had been raised. For example, rosiglitazone treatment increased the risk of myocardial infarction [60] and troglitazone, have been already withdrawn from the market due to hepatotoxicity.

\section{Dialysis}

Defronzo et al showed that dialysis of renal patients thrice weekly for 10 weeks normalizes IR. This improvement is correlated with the dialysis dose [61]. Similarly, peritoneal dialysis is as efficient as HD as regard to IR [22].

\section{Measurement of IR}

There are several arguments for recommending the routine measurement of serum insulin in renal patients (Table 3). IR is measured from the relationship between the sugar and the concomitant insulin level. Measurement of serum insulin level by the ELISA method is readily available and is not costly. Abnormal glucose level alone may not identify patients with increased IR, particularly in non-diabetic individuals. On the other hand, intensive blood glucose control doesn't improve CVD outcome in diabetic patients.

The main limitation for measurement of insulin in routine practice is the lack of standardization of insulin immunoassay. In 2007, the American Diabetic Association compared 12 commercially available methods to measure insulin [62]. They reported that, although all the methods were specific to insulin, there was a very high range of within-assay coefficient of variation (CVs) [3.7 - 39\%] and among-assay CVs $[12-66 \%]$, even with the use of a common insulin preparation. Some of the kits cross-react with intact pro-insulin and split it at different degrees.

\section{Conclusion}

IR is a treatable disease [63] that predicts future cardiovascular events in both renal and non-renal patients. It is more prevalent in patients with renal disease, particularly those with previous CVD. The 
above evidence supports the general notion that IR has a deleterious effect on the progression of kidney disease. It also supports the recommendation to measure IR in clinical practice to identify patients at risk for future cardiovascular events, particularly those with renal diseases. This notion is supported by the ease of measurement of both serum glucose and insulin levels. IR can be modified by pharmacological therapy, increased physical activity, and by weight reduction.

\section{References}

1. Katz A, Nambi SS, Mather K, Baron AD, Follmann DA, Sullivan G, Quon MJ. Quantitative insulin sensitivity check index: a simple, accurate method for assessing insulin sensitivity in humans. J Clin Endocrinol Metab. 2000;85(7):2402-10.

2. Mann JF, Gerstein HC, Pogue J, Bosch J, Yusuf S. Renal insufficiency as a predictor of cardiovascular outcomes and the impact of ramipril: the HOPE randomized trial. Ann Intern Med. 2001;134(8):629-36.

3. Shinohara K, Shoji T, Emoto M, Tahara H, Koyama $\mathrm{H}$, Ishimura E, Miki T, Tabata T, Nishizawa Y. Insulin resistance as an independent predictor of cardiovascular mortality in patients with end-stage renal disease. J Am Soc Nephrol. 2002;13(7):1894-900.

4. Kato Y, Hayashi M, Ohno Y, Suzawa T, Sasaki T, Saruta T. Mild renal dysfunction is associated with insulin resistance in chronic glomerulonephritis. Clin Nephrol. 2000;54(5):366-73.

5. Chen J, Muntner P, Hamm LL, Fonseca V, Batuman V, Whelton PK, He J. Insulin resistance and risk of chronic kidney disease in nondiabetic US adults. J Am Soc Nephrol. 2003;14(2):469-77.

6. Onat A, Hergenç G, Uyarel H, Ozhan H, Esen AM, Karabulut A, Albayrak S, Can G, Keles I. Association between mild renal dysfunction and insulin resistance or metabolic syndrome in a random nondiabetic population sample. Kidney Blood Press Res. 2007;30(2):88-96.

7. Ikee R, Hamasaki Y, Oka M, Maesato K, Mano T, Moriya H, Ohtake T. Kobayashi S. Glucose Metabolism, Insulin Resistance, Renal Pathology in Non-Diabetic Chronic Kidney Disease. Nephron Clin Pract. 2008;108(2):c163-8.

8. Sit D, Kadiroglu AK, Kayabasi H and Yilmaz ME. The prevalence of insulin resistance in nondiabetic nonobese patients with chronic kidney disease. Adv Ther. 2006;23(6):988-98.
9. Sit D, Kadiroglu AK, Yilmaz ME, Kara IH, Isikoglu B. The prevalence of insulin resistance and its relationship between anemia, secondary hyperparathyroidism, inflammation, and cardiac parameters in chronic hemodialysis patients. Ren Fail. 2005;27(4):403-7.

10. Chen J, Muntner P, Hamm LL, Jones DW, Batuman V, Fonseca V, Whelton PK, He J. The metabolic syndrome and chronic kidney disease in U.S. adults. Ann Intern Med. 2004;140(3):167-74.

11. Eldin WS, Ragheb A, Klassen J, Shoker A. Evidence for Increased Risk of Prediabetes in the Uremic Patient. Nephron Clin Pract. 2007;108(1):c47-55.

12. Kaartinen K, Syrjänen J, Pörsti I, Harmoinen A, Pasternack A, Niemelä H, Niemela O, Mustonen J. Insulin resistance and the progression of IgA glomerulonephritis. Nephrol Dial Transplant. 2007;22(3):778-83.

13. Becker B, Kronenberg F, Kielstein JT, Haller H, Morath C, Ritz E, Fliser D; MMKD Study Group. Renal insulin resistance syndrome, adiponectin and cardiovascular events in patients with kidney disease: the mild and moderate kidney disease study. J Am Soc Nephrol. 2005;16(4):1091-8.

14. Gatti A, Morini E, Cosmo SD, Maiani F, Mandosi E, Fallarino M, Morano S, Trischitta V. Metabolic syndrome is not a risk factor for kidney dysfunction in obese nondiabetic subjects. Obesity. 2008;16(4):899-901.

15. Satirapoj B, Supasyndh O, Boonyavarakul A, Luesutthiviboon L, Choovichian P. The correlation of insulin resistance and renal function in non diabetic chronic kidney disease patients. J Med Assoc Thai. 2005;88 Suppl 3: S97-104.

16. Trirogoff ML, Shintani A, Himmelfarb J, Ikizler TA. Body mass index and fat mass are the primary correlates of insulin resistance in nondiabetic stage 3-4 chronic kidney disease patients. Am J Clin Nutr. 2007;86(6):1642-8.

17. Charlesworth JA, Kriketos AD, Jones JE, Erlich $\mathrm{JH}$, Campbell LV, Peake PW. Insulin resistance and postprandial triglyceride levels in primary renal disease. Metabolism. 2005;54(6):821-8.

18. Spaia S, Pangalos M, Askepidis N, Pazarloglou M, Mavropoulou E, Theodoridis S, Dimitrakopoulos K, Milionis A, Vayonas G. Effect of short-term rHuEPO treatment on insulin resistance in hemodialysis patients. Nephron. 2000;84(4):320-5.

19. Prasad GV, Kim SJ, Huang M, Nash MM, Zaltzman JS, Fenton SS, Cattran DC, Cole EH, Cardella CJ. Reduced incidence of new-onset diabetes mellitus after 
renal transplantation with 3-hydroxy-3-methylglutarylcoenzyme a reductase inhibitors (statins). Am J Transplant. 2004;4(11):1897-903.

20. Kinoshita M, Nakaya Y, Harada N, Takahashi A, Nomura M, Bando S. Combination therapy of exercise and angiotensin-converting enzyme inhibitor markedly improves insulin sensitivities in hypertensive patients with insulin resistance. Circ J. 2002;66(7):655-8.

21. Abe M, Kaizu K, Matsumoto K. Plasma insulin is removed by hemodialysis: evaluation of the relation between plasma insulin and glucose by using a dialysate with or without glucose. Ther Apher Dial. 2007;11:280-7.

22. Kobayashi S, Maejima S, Ikeda T, Nagase M. Impact of dialysis therapy on insulin resistance in end-stage renal disease: comparison of hemodialysis and continuous ambulatory peritoneal dialysis. Nephrol Dial Transplant. 2000;15(1):65-70.

23. ter Maaten JC, Bakker SJ, Serné EH, ter Wee PM, Donker AJ, Gans RO. Insulin's acute effects on glomerular filtration rate correlate with insulin sensitivity whereas insulin's acute effects on proximal tubular sodium reabsorption correlation with salt sensitivity in normal subjects. Nephrol Dial Transplant. 1999;14(10):235763.

24. Ter Maaten JC, Bakker SJ, Serné EH, Moshage HJ, Donker AJ, Gans RO. Insulin-mediated increases in renal plasma flow are impaired in insulin-resistant normal subjects. Eur J Clin Invest. 2000;30(12):1090-8.

25. Rerolle JP, Hertig A, Nguyen G, Sraer JD, Rondeau EP. Plasminogen activator inhibitor type 1 is a potential target in renal fibrogenesis. Kidney Int. 2000;58(5):184150 .

26. Komers R, Anderson S. Paradoxes of nitric oxide in the diabetic kidney. Am J Physiol Renal Physiol. 2003;284(6):F1121-37

27. Facchini FS, Hua NW, Reaven GM, Stoohs RA. Hyperinsulinemia: the missing link among oxidative stress and age-related diseases? Free Radic Biol Med. 2000;29(12):1302-6.

28. Oberg BP, McMenamin E, Lucas FL, McMonagle E, Morrow J, Ikizler TA, Himmelfarb J. Increased prevalence of oxidant stress and inflammation in patients with moderate to severe chronic kidney disease. Kidney Int. 2004;65(3):1009-16.

29. Muntner P, Coresh J, Smith JC, Eckfeldt J, Klag MJ. Plasma lipids and risk of developing renal dysfunction: the atherosclerosis risk in communities study. Kidney Int. 2000;58(1):293-301.

30. Pinkau T, Hilgers KF, Veelken R, Mann JF. How does minor renal dysfunction influence cardiovascular risk and the management of cardiovascular disease? J Am Soc Nephrol. 2004;15(3):517-23.

31. Stuhlinger MC, Abbasi F, Chu JW, Lamendola C, McLaughlin TL, Cooke JP, Reaven GM, Tsao PS. Relationship between insulin resistance and an endogenous nitric oxide synthase inhibitor. JAMA. 2002;287(11):1420-6.

32. Rotter V, Nagaev I, Smith U. Interleukin-6 (IL-6) induces insulin resistance in 3T3-L1 adipocytes and is, like IL-8 and tumor necrosis factor-alpha, overexpressed in human fat cells from insulin-resistant subjects. J Biol Chem. 2003;278(46):45777-84.

33. Moller DE. Potential role of TNF-alpha in the pathogenesis of insulin resistance and type 2 diabetes. Trends Endocrinol Metab. 2000;11(6):212-7.

34. Bloomgarden ZT. Insulin resistance, dyslipidemia, and cardiovascular disease. Diabetes Care. 2007;30(8):216470.

35. DunnEJ, GrantPJ. Type2 diabetes: an atherothrombotic syndrome. Curr Mol Med. 2005;5(3):323-32.

36. Ilercil A, Devereux RB, Roman MJ, Paranicas M, O'Grady MJ, Welty TK, Robbins DC, Fabsitz RR, Howard BV, Lee ET. Relationship of impaired glucose tolerance to left ventricular structure and function: The Strong Heart Study. Am Heart J. 2001;141(6):992-8.

37. Colao A, Baldelli R, Marzullo P, Ferretti E, Ferone D, Gargiulo P, Petretta M, Tamburrano G, Lombardi G, Liuzzi A. Systemic hypertension and impaired glucose tolerance are independently correlated to the severity of the acromegalic cardiomyopathy. J Clin Endocrinol Metab. 2000;85(1):193-9.

38. Young ME, McNulty P, Taegtmeyer H. Adaptation and maladaptation of the heart in diabetes: Part II: potential mechanisms. Circulation. 2002;105(15):1861-70.

39. Young ME, Patil S, Ying J, Depre C, Ahuja HS, Shipley GL, Stepkowski SM, Davies PJ, Taegtmeyer $\mathrm{H}$. Uncoupling protein 3 transcription is regulated by peroxisome proliferator-activated receptor (alpha) in the adult rodent heart. FASEB J. 2001;15(3):833-45.

40. Campbell FM, Kozak R, Wagner A, Altarejos JY, Dyck JR, Belke DD, Severson DL, Kelly DP, Lopaschuk GD. A role for peroxisome proliferator-activated receptor alpha (PPARalpha ) in the control of cardiac malonyl-CoA 
levels: reduced fatty acid oxidation rates and increased glucose oxidation rates in the hearts of mice lacking PPARalpha are associated with higher concentrations of malonyl-CoA and reduced expression of malonyl-CoA decarboxylase. J Biol Chem. 2002;277(6):4098-103.

41. Bonora E, Kiechl S, Willeit J, Oberhollenzer F, Egger G, Meigs JB, Bonadonna RC, Muggeo M. Insulin resistance as estimated by homeostasis model assessment predicts incident symptomatic cardiovascular disease in caucasian subjects from the general population: the Bruneck study. Diabetes Care. 2007;30(2):318-24.

42. Bonora E, Kiechl S, Willeit J, Oberhollenzer F, Egger G, Meigs JB, Bonadonna RC, Muggeo M. Insulin resistance as estimated by homeostasis model assessment predicts incident symptomatic cardiovascular disease in caucasian subjects from the general population: the Bruneck study. Diabetes Care. 2007;30(2):318-24.

43. Axelsson J, Bergsten A, Qureshi AR, Heimbürger O, Bárány $\mathrm{P}$, Lönnqvist $\mathrm{F}$, Lindholm $\mathrm{B}$, Nordfors L, Alvestrand A, Stenvinkel P. Elevated resistin levels in chronic kidney disease are associated with decreased glomerular filtration rate and inflammation, but not with insulin resistance. Kidney Int. 2006;69(3):596-604.

44. de Vinuesa SG, Goicoechea M, Kanter J, Puerta M, Cachofeiro V, Lahera V, Gómez-Campderá F and Luño J. Insulin resistance, inflammatory biomarkers, and adipokines in patients with chronic kidney disease: effects of angiotensin II blockade. J Am Soc Nephrol. 2006;17(12 Suppl 3):S206-12.

45. Bodlaj G, Berg J, Pichler R, Biesenbach G. Prevalence, severity and predictors of HOMA-estimated insulin resistance in diabetic and nondiabetic patients with end-stage renal disease. J Nephrol. 2006;19(5):60712.

46. Hanley AJ, Williams K, Stern MP, Haffner SM. Homeostasis model assessment of insulin resistance in relation to the incidence of cardiovascular disease: the San Antonio Heart Study. Diabetes Care. 2002;25(7):117784.

47. Bonora E, Formentini G, Calcaterra F, Lombardi S, Marini F, Zenari L, Saggiani F, Poli M, Perbellini S, Raffaelli A, Cacciatori V, Santi L, Targher G, Bonadonna R, Muggeo M. HOMA-estimated insulin resistance is an independent predictor of cardiovascular disease in type 2 diabetic subjects: prospective data from the Verona Diabetes Complications Study. Diabetes Care. 2002;25(7):1135-41.
48. Hsu CY, McCulloch CE, Iribarren C, Darbinian J and Go AS. Body mass index and risk for end-stage renal disease. Ann Intern Med. 2006;144(1):21-8.

49. Polak J, Kovacova Z, Holst C, Verdich C, Astrup A, Blaak E, Patel K, Oppert JM, Langin D, Martinez JA, Sorensen TI, Stich V. Total adiponectin and adiponectin multimeric complexes in relation to weight loss-induced improvements in insulin sensitivity in obese women: the NUGENOB study. Eur J Endocrinol. 2008;158(4):53341.

50. Johansen KL, Young B, Kaysen GA, Chertow GM. Association of body size with outcomes among patients beginning dialysis. Am J Clin Nutr. 2004;80(2):324-32.

51. Kalantar-Zadeh K, Kopple JD. Obesity paradox in patients on maintenance dialysis. Contrib Nephrol. 2006; 151:57-69.

52. Naish P. Physical dysfunctioning - the case for rehabilitation. Br J Renal Med. 1999;4(1):6-8.

53. Johansen KL, Kutner NG, Young B, Chertow GM. Association of body size with health status in patients beginning dialysis. Am J Clin Nutr. 2006;83(3):543-9.

54. Cook SA, MacLaughlin H, Macdougall IC. A structured weight management programme can achieve improved functional ability and significant weight loss in obese patients with chronic kidney disease. Nephrol Dial Transplant. 2008;23(1):263-8.

55. Tuzcu A, Bahceci M, Yilmaz E, Bahceci S, Tuzcu S. The comparison of insulin sensitivity in nondiabetic hemodialysis patients treated with and without recombinant human erythropoietin. Horm Metab Res. 2004;36(10):716-20.

56. Iliescu EA, White CA, Toffelmire EB, Hudson RW. Effect of intravenous iron on insulin sensitivity in dialysis patients. Hemodial Int. 2007;11(4):492-3.

57. Guerre-Millo M, Gervois P, Raspé E, Madsen L, Poulain P, Derudas B, Herbert JM, Winegar DA, Willson TM, Fruchart JC, Berge RK, Staels B. Peroxisome proliferator-activated receptor alpha activators improve insulin sensitivity and reduce adiposity. J Biol Chem. 2000;275(22):16638-42.

58. Schneider CA, Ferrannini E, Defronzo R, Schernthaner G, Yates J, Erdmann E. Effect of pioglitazone on cardiovascular outcome in diabetes and chronic kidney disease. J Am Soc Nephrol. 2008;19(1):182-7.

59. Deray G, Izzedine H, Launay-Vacher V and Bagnis C. [Kidney and glitazones]. Ann Endocrinol (Paris). 2005;66(2 Pt 2):1S81-90. Review. French. 
60. Nissen SE, Wolski K. Effect of rosiglitazone on the risk of myocardial infarction and death from cardiovascular causes. N Engl J Med. 2007;356(24):2457-71.

61. Mínguez C, López-Suárez A, Soto MJ, Ceballos M, Bailén MA, Benítez E, Girón-González JA. [Renal failure and insulin resistance: effect of the dialysis dose]. Rev Clin Esp. 2007;207(9):440-4. Spanish.
62. Marcovina S, Bowsher RR, Miller WG, Staten M, Myers G, Caudill SP, Campbell SE, Steffes MW; Insulin Standardization Workgroup. Standardization of insulin immunoassays: report of the American Diabetes Association Workgroup. Clin Chem. 2007;53(4):711-6.

63. Stefanović V, Nesić V, Stojimirović B. Treatment of insulin resistance in uremia. Int $\mathrm{J}$ Artif Organs. 2003;26(2):100-4. 